\title{
Platelet-rich plasma for tendinopathy and osteoarthritis: a narrative review
}

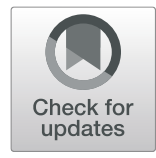

Rilind Shala(D)

\begin{abstract}
Background: Musculoskeletal disorders include a wide range of degenerative and inflammatory problems, which can affect any part of the muscular and skeletal system. Platelet-rich plasma (PRP) has been a breakthrough in musculoskeletal medicine, especially with its effects to speed up soft tissue, cartilage, and bone healing. It is now thought that stem cells are able to reverse the degenerative process and promote rapid healing. Platelet-rich plasma (PRP) has received special attention in treating tendinopathy and osteoarthritis. This review aims to do a comprehensive review of the scientific evidence for the efficiency of PRP application in tendinopathy and osteoarthritis.

Main body of the abstract: In osteoarthritis treatment, platelet-rich plasma is thought to influence the whole joint environment by increasing chondrocyte proliferation. The injection of autologous PRP into the joint space and surrounding soft tissues delivers a concentrated dose of these growth factors, which accelerate the healing process and reduce pain.

Short conclusion: Many studies report some benefits in regard to pain and functionality, especially in tendinopathy, but further investigations are needed to incorporate PRP into clinical practice and be a common form of therapy for tendinopathy and osteoarthritis. Caution should be applied with any treatment we use in clinical practice, especially with PRP and other forms of injections.
\end{abstract}

Keywords: Platelet-rich plasma, Tendinopathy, Osteoarthritis

\section{Background}

Musculoskeletal disorders include a wide range of degenerative and inflammatory problems, which can affect any part of the muscular and skeletal system. Although they have a minimal impact on mortality, musculoskeletal disorders have a considerable influence on pain and disability.

The financial costs associated with musculoskeletal conditions are a big problem [1]. In the USA in 1992, the total cost of musculoskeletal and associated conditions was $\$ 149.4$ billion, or the equivalent of $2.5 \%$ of that year's Gross National Product (GNP) [2].

Many treatment strategies are developed and still developing to resist these major consequences that musculoskeletal (MsK) conditions bring with them. The

Correspondence: rilind.shala1@student.uni-pr.edu

Department of Physiotherapy, Faculty of Medicine, University of Prishtina, Rr. Bulevardi i Dëshmorëve, p.n., 10000 Pristina, Kosovo consequences of MsK disorders are also distributed to not only loss of money, but the loss of work. With that in mind, researchers are developing new methods to address musculoskeletal disorders and to reduce cost and time off work. These new methods range from traditional exercises to something that in its core is blood therapy, called platelet-rich plasma (PRP) [3].

Platelet-rich plasma (PRP) has been a breakthrough in musculoskeletal medicine, especially with its effects to speed up soft tissue, cartilage, and bone healing [3]. Tissue healing is slow, and sometimes a stubborn process. Finding something to accelerate tissue healing is important, not only for athletes but also for general people who suffer from tendinopathy, osteoarthritis, acute muscle injuries, etc. Despite the limited scientific evidence, musculoskeletal practitioners began using PRP for the management of cartilage problems as early as $2003[4,5]$.
Springer Open

(c) The Author(s). 2021 Open Access This article is licensed under a Creative Commons Attribution 4.0 International License, which permits use, sharing, adaptation, distribution and reproduction in any medium or format, as long as you give appropriate credit to the original author(s) and the source, provide a link to the Creative Commons licence, and indicate if changes were made. The images or other third party material in this article are included in the article's Creative Commons licence, unless indicated otherwise in a credit line to the material. If material is not included in the article's Creative Commons licence and your intended use is not permitted by statutory regulation or exceeds the permitted use, you will need to obtain permission directly from the copyright holder. To view a copy of this licence, visit http://creativecommons.org/licenses/by/4.0/. 
Regenerative medicine is being studied more intensively in the field of sports medicine and physiotherapy. It is now thought that stem cells are able to reverse the degenerative process and promote rapid healing $[6,7]$.

PRP is a simple and minimally invasive form of application for growth factor release. Growth factors have an influence on different aspects of tendon repair, including angiogenesis, chemotaxis, and cell proliferation by activating intracellular signal-transduction pathways [8-10].

Platelet alpha granules have within stored many bioactive molecules such as insulin-like GF (IGF-I), hepatocyte GF (HGF), fibroblast GF (FGF-2), and transforming GF (TGF-b1), which may be key regulators of muscle regeneration and myogenesis $[11,12]$. That is the rationale of using PRP, as a form of regenerative medicine in diseases like osteoarthritis.

PRP therapy provides delivery of a highly concentrated cocktail of growth factors to speed up healing [13]. The transforming growth factor present in PRP has been linked with chondrogenesis in cartilage repair [13-15].

Platelet-rich plasma nowadays is used in many fields, including sports medicine, orthopedics, ophthalmology, dentistry, dermatology, etc. [7].

The rationale for using platelets in so many fields is because PLTs constitute a reservoir of critical GFs and cytokines, which may govern and regulate the tissue healing process that is quite similar in all kinds of tissues [7]. These cytokines mediate the initiation of neovascularization, tenocyte proliferation, fibroblast proliferation, and further recruitment of inflammatory cells [16-18].

PRP may also have an inhibitory effect on some proinflammatory cytokines that may be detrimental to the early stages of healing, specifically through suppression of IL-1 release from activated macrophages $[16,19]$.

As with all biological methods, researchers are looking for that one thing that would finally accelerate the slow and annoying tissue healing, which is often incomplete. This review aims to do a comprehensive review of the scientific evidence for the efficiency of PRP application in tendinopathy and osteoarthritis. We searched key databases (PubMed, Google Scholar, Web of Science, Scopus, and Cochrane). Search terms relating to PRP, osteoarthritis, and tendinopathy were combined. Reference lists of identified articles, which must have been available in English, were then used to identify related references.

\section{Main text}

\section{Role of PRP in tendinopathy}

Platelet-rich plasma (PRP) has received special attention in treating tendinopathy.

Tendons have a slow healing rate and poor vascularity. The rehabilitation process by patients is described as "annoying," both because of the longevity and unpredictable results, so the expectations are high for this new technology. In the past, tendon and muscle-related disorders were treated by injecting corticosteroids; however, the research found out that this is associated with many risks, including tendon rupture [20]. Knowing the irritating clinical pathway of tendinopathy for both patients and clinicians, PRP could be a "life savior" for tendinopathy suffers. What does the research say?

The effects of PRP have been investigated for various tendon-related disorders. Growth factors derived from platelets are already applied for the treatment of tendinopathy to improve and accelerate healing and recovery [7]. The positive effects of PRP in tendon disorders have been reported in many animal studies [3].

In a study by Aspenberg et al., they found out that when injecting PRP into the transected rat Achilles tendon, tendon callus strength and stiffness will be increased by about 30\% after 1 week and mechanical testing indicated an improvement in the maturation of the tendon callus when compared with controls [21] (Fig. 1).

A review about basic science studies showed both positive in vitro (e.g., increased tenocyte proliferation, increased collagen production, induce the tenocyte differentiation) and in vivo (increased tendon healing) effects of PRP. It was also shown that PRP treatment of tendon cells in vitro could induce the release of HGF, which is a major anti-inflammatory growth factor [22].

The rationale of using PRP in tendinopathy lies in the role that various growth factors contained in the platelet alpha granules have, for example, TGF-b increases the expression of procollagen types I and III and mechanical properties. PDGF-BB, insulin-like growth factor 1 (IGF-1), vascular endothelial growth factor (VEGF), and B-FGF promote tendon cell proliferation and tendon healing [23-25]. PRP is also thought to be effective because when an injury happens, platelets are the "first responders" and thus PRP treatment may reproduce the natural wound healing process.

In a recent study done by Auriemma et al., they injected ultrasound-guided leukocyte-rich PRP into patients with chronic proximal hamstring tendinopathy. The majority of patients demonstrated $\geq 50 \%$ reduction of pain, and functional outcomes improved following injection of PRP [26].

With its positive effects on pain and functionality in patients with tendinopathy, PRP seems to be the perfect replacement for corticosteroid injections, which have been reported to increase the risk for tendon rupture, but is this really the case?

A case report by Redler et al. showed us a risk associated with using PRP for patellar tendinopathy. A football player underwent a series of 4 US-guided injections of autologous leukocyte-rich PRP, and after a while, a 

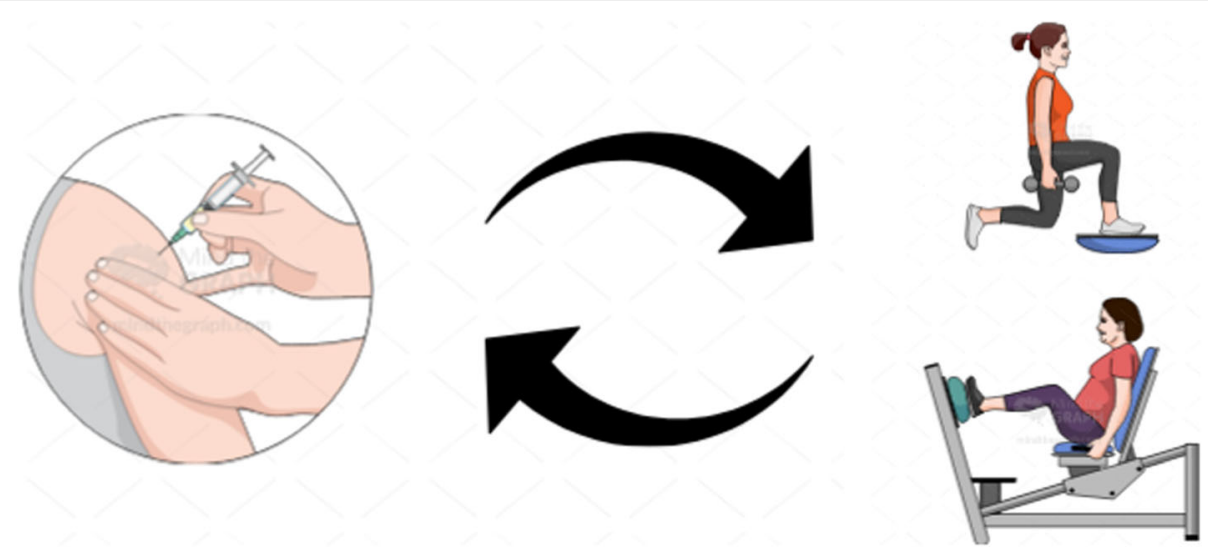

Fig. 1 Using PRP to increase adherence to physical activity

complete rupture in the middle of the patellar tendon was found, with severe degenerative changes of the tendon tissue [27].

The "Working Group for Clinical Tissue Regeneration" consisting of 95 members in a meeting gave their recommendations on the use of PRP in various MsK conditions. The experts represent the opinion in a large majority ( 82.5 and $80 \%$ ) that the use of PRP in acute and chronic tendinopathies can be useful, but expert opinion is not enough [28].

The use of PRP for the treatment of tendinopathy is a topic still greatly debated in the literature, and we have both positive and negative results from studies. Older studies show a large improvement in pain and functionality, while new randomized control trials question if there is a benefit associated with the use of PRP.

Filardo et al. published a case report of a partial tear of the Achilles tendon in a competitive athlete where surgical treatment was avoided in favor of a new biological approach. They applied autologous platelet growth factors through multiple platelet-rich plasma injections. Eighteen months later, he has participated regularly in all the season's games and received no further treatment for his tendon. The fast tissue repair, confirmed by magnetic resonance and ultrasound imaging, allowed a swift return to full functionality and competitive sports activity, suggesting a possible role of platelet growth factors in promoting rapid tendon healing with high-quality tissue [29].

Mishra and Pavelko compared a control group with chronic severe elbow tendinopathy who received injections of a local anesthetic with a group that used PRP. The patients who were treated with PRP injection had a $60 \%$ reduction in pain by 8 weeks and a $93 \%$ reduction in pain by the final follow-up, which ranged from 12 to 38 months [30].

Unfortunately, the same results are not reported in other studies. De Vos et al. reported that in Achilles tendinopathy, the clinical use of a PRP injection showed no benefit on pain and function. There were also no significant differences observed in the secondary outcome measures (subjective patient satisfaction and return to sports activity). As a result of this, they do not recommend this treatment for chronic midportion Achilles tendinopathy [31].

Schepull et al. showed that PRP did not significantly improve symptoms in patients with chronic Achilles tendinopathy when compared to the saline-treated group up to 1 year after the treatment [32].

Similar results were also found in a study by Kesikburun et al. Patients were randomized into a PRP group $(n=20)$ or placebo group $(n=20)$. Patients received an ultrasoundguided injection into the subacromial space. At 1-year follow-up, a PRP injection was found to be no more effective in improving quality of life, pain, disability, and shoulder range of motion than placebo in patients with chronic RCT who were treated with an exercise program [33].

A large number of factors related to patients also contribute to controversial PRP treatment outcomes. These may include age, gender, past medical history, disease and injury type, recovery plans, etc.

Many studies show a clear benefit of using PRP to improve pain and function in patients with tendinopathy, and many others show no clear benefit associated with using PRP, thus creating controversies in the efficacy of PRP (Table 1).

\section{Role of PRP in osteoarthritis}

Osteoarthritis (OA) is a common and disabling condition associated with pain and the loss of mobility that undermines the quality of life. Clinically, the condition can be identified by many clinical symptoms, for example, joint pain, tenderness, stiffness, and limitation of movement with effusion and variable degrees of local inflammation. Pain in osteoarthritis is not simply attributable to the structural changes in the joint, but it is the 
Table 1 PRP in tendinopathy: a review of the most recent studies

\begin{tabular}{|c|c|c|c|c|}
\hline Study & Diagnosis & Patients & F up & Results \\
\hline Auriemma et al. (2020) [26] & Hamstring tendinopathy & 22 & 6 months & $\geq 50 \%$ reduction of pain, functional outcomes improved \\
\hline Scott et al. (2019) [34] & Patellar tendinopathy & 61 & 12 months & $\begin{array}{l}\text { No more effective than saline for the improvement of } \\
\text { symptoms. }\end{array}$ \\
\hline Levy et al. (2018) [35] & Hamstring tendinopathy & 29 & 8 weeks & No improvement on clinical outcomes \\
\hline Liu et al (2019) [36] & Achilles tendinopathy & 189 & - & Not superior to placebo treatment \\
\hline Ibrahim et al. (2018) [37] & rotator cuff tendinopathy & 30 & 7 weeks & A significant improvement of pain, SDQ and ROM \\
\hline Chen et al. (2020) [38] & Rotator cuff tears & 1116 & - & Retear rates were significantly decreased \\
\hline Linnanmäki et al. (2020) [39] & Lateral epicondylitis & 119 & 52 weeks & no improved pain or function \\
\hline Huang et al. (2020) [40] & $\begin{array}{l}\text { Elbow epicondylitis and } \\
\text { plantar fascitiis }\end{array}$ & 1268 & - & Long-term functional improvement \\
\hline Alkhatib et al. (2020) [41] & Plantar fasciitis & 389 & - & Effective and safe treatment option \\
\hline Lin et al. (2020) [42] & Rotator cuff tendinopathy & 283 & 24 weeks & Effective in reducing pain in the long term (over 2 weeks) \\
\hline
\end{tabular}

result of coaction between structural change, peripheral, and central pain processing mechanisms [43, 44].

An estimated 30.8 million adults in the USA and 300 million individuals worldwide are living with OA $[45,46]$. $\mathrm{OA}$ is most notable for its effect on articular cartilage, which gets severely degraded throughout the disease.

OA often demonstrates joint space narrowing, osteophyte formation, subchondral sclerosis, and cysts. It is worth noting that the degree of structural damage noted on imaging and the presence of pain is not always in line with the symptoms of OA. Some individuals with severe pain have an absence of findings on imaging and vice versa [47]. The joint capsule, tendons, retinacula, fat pads, synovium, subchondral bone, and ligaments contain type III and type IVa fibers that contribute to pain generation in OA [48].

Traditionally, osteoarthritis treatment consists of pain management with joint replacement for end-stage disease [43, 49-51]. This approach does not address the morbidity associated with an early disease or the limitations of arthroplasty surgery, which include the possibility of adverse outcomes and the finite lifespan of prostheses [43].

Various approaches have been proposed as noninvasive treatment with mediocre success rates, but none has clearly shown an ability to alter the natural history of this condition [52]. Recently, platelet-rich plasma (PRP) has been attracting attention as an innovative and favorable procedure to stimulate repair damaged cartilage, due to the pools of growth factors (GFs) stored in $\alpha$-granules of platelets, which have been found to take part in the regulation of articular cartilage [52, 53]. In OA treatment, PRP is thought to have an influence on the whole joint environment by increasing chondrocyte proliferation. The injection of autologous PRP into the joint space and surrounding soft tissues delivers a concentrated dose of these growth factors, which accelerate the healing process and reduce pain [54].
Kon et al. first reported on intra-articular PRP injections to 115 osteoarthritic knees, for a total of 3 sets of injections. International Knee Documentation Committee scores demonstrated statistically significant improvement at 6- and 12-month follow-up. They suggest that PRP may be useful for the treatment of early degenerative articular pathology of the knee [55].

A systematic review by Meheux et al. showed positive results of PRP in knee OA. They reported that "PRP injection results in significant clinical improvements up to 12 months post-injection. Clinical outcomes and WOMAC scores are significantly better after PRP versus hyaluronic acid at 3 to 12 months post-injection" [56].

In 2018, Cook and Smith published a paper entitled "Why PRP should be your first choice for injection therapy in treating KOA." The authors reported that recent research on PRP injections in knee osteoarthritis had shown the injections' efficacy and safety in all stages of the disease, but better efficacy was shown when PRP was injected in the early stages of the disease [57].

Gobbi et al. followed prospectively 50 patients with symptomatic knee OA of grades 1-3 per KellgrenLawrence classification. All patients were treated with 2 intra-articular injections with autologous PRP. They found out that a significant number of patients had reduced pain after two injections of PRP and returned to the prior level of activity at 12 months follow-up. In the same group, they found that at 2 years, PRP-treated patients continued to have improved pain control and mobility [58].

Similar results have been reported also by Patel et al., where they found that in the short term PRP injection is more effective than a placebo for relieving pain and stiffness and improving knee functions in early knee OA [59].

If PRP has effects on healing, do we see radiological changes after an injection? 
Raeissadat et al. did a double-blind randomized clinical trial with patients who had bilateral knee osteoarthritisgrade 1, 2, and 3 to see the effects of PRP on cartilage. MRI changes including patellofemoral cartilage volume, synovitis, and medial and lateral meniscal disintegrity showed significant improvement after treatment with PRP [60].

A study by Ahmad et al. looked to determine whether the clinical outcomes of PRP are associated with changes in the ultrasonography structural appearance in 2 groups of PRP and hyaluronic acid injections. In both groups, after 3 and 6 months of follow-up, clinical improvement was observed with the PRP group showing better improvement than the hyaluronic acid group. As per the ultrasonography examination, the clinical outcomes of the intra-articular injections of PRP included improved synovial hypertrophy and vascularity scores, and less frequency of effusion [61].

In 2018, Buendía-López et al. studied the effect of PRP, hyaluronic acid, and NSAIDS on MRI findings. Ninety-eight patients completed the study, from which 33 were in the NSAID group, 32 in the hyaluronic acid group, and 33 in the PRP group. The PRP group received a 5-ml PRP injection. The overall progression in the Kellgren-Lawrence score for the whole group was $17 \%$ from grade 1 to grade 2, from baseline to week 52 , and there was no worsening from grade 2 nor 2 or more grades from grade. Cartilage thickness showed a reduction in all tibial and femoral subregions in the three groups, from baseline to week 52 [62].

Samara et al. studied a platelet-derived product named autologous platelet lysates if it can induce positive structural changes as detected by magnetic resonance imaging (MRI) in patients with early and intermediate knee osteoarthrosis. In the follow-up, after PL injection at 52 weeks, all patients showed an increase in MRI-based cartilage thickness measurement which was significant [63].

Research shows that patient age impacts PRP outcomes, where younger individuals are reported to have greater benefits. Kon et al. found that better results were achieved in younger and more active patients with a low degree of cartilage degeneration, and a worse outcome was obtained in more degenerated joints and older patients [64].

Platelet-rich plasma and other forms of injections represent a major paradigm shift and advancement in the treatment of knee osteoarthritis. However, there remains a need for strong, sufficiently, randomized controlled trials to justify its use over other forms of treatments (physical therapy, weight loss, surgery, corticosteroid, and viscosupplementation).

The research for PRP leaves place to debate, with both positive and negative results (Table 2). Practitioners should be mindful of the forms of treatments they use and be careful to treat the patient in a multidimensional, biopsychosocial manner, rather than a "one-size-fits-all" approach.

\section{Discussion}

For over 20 years, PRP has been used in a variety of conditions with promising implications. Regenerative medicine has opened a new emerging window for the restoration of tissues with severe injuries using plateletrich plasma (PRP).

PRP currently is considered investigational because there is insufficient data to support the use of PRP for all indications. The possibility of using patients' growth factors to enhance reparative processes in tissues with low healing potential, and the safety of these methods, explain the wide use of this biological approach [7].

We argue that patients should only be offered PRP for musculoskeletal injuries within the context of welldesigned clinical trials, with informed consent, highquality verbal explanations, and supporting written information [75]. Even with recent advances in understanding PRP, there are still many unknowns about the factors and processes that make the treatment effective for musculoskeletal conditions. As we have seen from our study, the data is pretty much all over the place now, with studies both reporting positive effects, and others showing small or no benefits at all. Currently, PRP therapies have remained unsatisfactory in terms of therapeutic expectations because many individuals do not acquire sufficient benefits from PRP.

While limited, current evidence suggests the use of PRP to be safe. Medical ethics is anchored by the concepts of beneficence (doing good) and nonmaleficence (do no harm). Because it is an autologous preparation, PRP is inherently safe and therefore free from concerns over transmittable diseases such as HIV, hepatitis, West Nile fever, and Cruetzfeldt-Jacob disease (CJD) [76]. Because PRP is derived from your own blood ("autologous" transplantation), there is no chance of having an allergy or immune reaction either.

In recent years, there has been a shift in treatment approaches for musculoskeletal conditions. The focus is being shifted toward a more exercise-based, biopsychosocial approach with using active treatments and a patient-centered focus and using less a "one-size-fits-all" approach.

We now know that exercise is medicine, and is helpful in 26 health conditions (e.g., type 2 diabetes, hypertension, coronary heart disease, pulmonary diseases, musculoskeletal disorders (osteoarthritis, osteoporosis, back pain, rheumatoid arthritis)) [77]. Best practice recommendations for musculoskeletal pain now recommend that care should be patient-centered, and that management of MsK pain should be by addressing physical 
Table 2 PRP in osteoarthritis: a review of the most recent studies

\begin{tabular}{|c|c|c|c|c|}
\hline Study & Diagnosis & Patients & F up & Results \\
\hline Filardo et al. (2020) [65] & Knee osteoarthritis & 2628 & - & PRP injections provide better results than other injectable options \\
\hline Migliorini et al. (2020) [66] & Knee osteoarthritis & 3463 & 12 months & $\begin{array}{l}\text { PRP demonstrated the best overall outcome compared to steroids, } \\
\text { hyaluronic acid and placebo for patients with knee osteoarthrosis }\end{array}$ \\
\hline Zhao et al. (2020) [67] & Knee osteoarthritis & 941 & - & PRP combined with HA may have promising clinical effects on KOA \\
\hline Abdelfattah et al. (2020) [68] & $\begin{array}{l}\text { Carpometacarpal } \\
\text { osteoarthritis }\end{array}$ & 13 & - & HA provide a superior improvement with respect to PRP at 12 weeks \\
\hline Kumar et al. (2020) [69] & Knee osteoarthritis & 1575 & - & $\begin{array}{l}\text { PRP is more effective than hyaluronic acid in pain relief and improving } \\
\text { the quality of life in mild to moderate osteoarthritis of the knee joint. }\end{array}$ \\
\hline Gilat et al. (2020) [70] & Knee osteoarthritis & - & - & $\begin{array}{l}\text { PRP may provide greater therapeutic relief, particularly with the use of } \\
\text { leukocyte-poor (LP-PRP) formulations. }\end{array}$ \\
\hline Chen et al. (2020) [71] & Knee osteoarthritis & 1350 & - & PRP reduced long-term pain and improved knee joint function. \\
\hline $\begin{array}{l}\text { Medina-Porqueres et al. } \\
\text { (2020) [72] }\end{array}$ & Hip osteoarthritis & 334 & - & $\begin{array}{l}\text { Moderate to significant improvements in pain and function when } \\
\text { compared with other similar procedures. }\end{array}$ \\
\hline Hohmann et al. (2020) [73] & Knee osteoarthritis & 1248 & - & PRP is superior to HA for symptomatic knee pain at 6 and 12 months \\
\hline Dong et al. (2020) [74] & $\begin{array}{l}\text { Knee and hip } \\
\text { osteoarthritis }\end{array}$ & - & - & $\begin{array}{l}\text { Intra-articular PRP injection provided better effects than other } \\
\text { intra-articular injections for OA patients }\end{array}$ \\
\hline
\end{tabular}

activity and/or exercise [78]. These recommendations come to play especially when we have conditions like osteoarthritis and tendinopathy, where we could benefit from a more holistic approach, targeting activity, exercise, and self-management.

Exercise therapy is also rated highly in tendinopathy, whereby the core of the problem is managing load.

Numerous guidelines support using exercise, physical activity, and education as the main treatment for MsK conditions [79, 80]. Whereas some guidelines do not support the use of PRP. A Cochrane review stated that "the available evidence is insufficient to support the use of PRP for treating musculoskeletal soft tissue injuries or show whether the effects of PRP vary according to the type of injury. Any future research in this area should bear in mind the several studies currently going on and should consider the need for standardization of the PRP preparation" [81].

Additional research into the potential effects of PRP is warranted to ensure the patient's safety, and so that clear, evidence-based guidelines can be implemented regarding the use of PRP. Despite its exciting potential, there is currently no consensus regarding therapeutic guidelines for the utilization of PRP. Further investigations are needed to optimize platelet dosing, cellular composition, and postprocedure rehabilitation protocols for PRP, as well as customized methods for preparation and application which are potential targets for future research.

\section{Conclusion}

PRP use has gained popularity for the treatment of musculoskeletal disorders because of its low cost, minimally invasive nature, and simplicity. The literature itself contains some controversies about the benefit that PRP provides in treating tendinopathy and osteoarthritis. As continued interest in the use of PRP for the treatment of musculoskeletal diseases will advance, there should be more clinical studies done to see if it has any long-term benefit, with many studies only reporting short-term outcomes, seen with many other injections. Many studies report some benefits in regards to pain and functionality, especially in tendinopathy, but further investigations are needed to incorporate PRP into clinical practice and be a common form of therapy for tendinopathy and osteoarthritis. Caution should be applied with any treatment we use in clinical practice, especially with PRP and other forms of injections. It is been thoroughly demonstrated that people get stronger placebo effects from treatments like PRP because they expect them to be more powerful than a simple exercise, and of the bias that its biological, so it should work.

\section{Abbreviations}

PRP: Platelet-rich plasma; MsK: Musculoskeletal; OA: Osteoarthritis; PDGF: Platelet-derived growth factor; IGF-1: Insulin-like growth factor 1; VEGF: Vascular endothelial growth factor; BFGF: Basic fibroblast growth factor; TGF-b: Transforming growth factor-beta

\section{Acknowledgements}

N/A

Conflict of interest

We declare that we have no conflicts of interest to disclose.

Author's contributions

All authors have read and approved the final manuscript. I'm the sole author of this paper.

Funding

Self-funding. No funding was received. 


\section{Availability of data and materials}

Not applicable.

\section{Declarations}

Ethics approval and consent to participate N/A

\section{Consent for publication}

N/A

\section{Competing interests}

N/A

\section{Received: 21 December 2020 Accepted: 6 April 2021}

Published online: 18 May 2021

\section{References}

1. Lee P. The economic impact of musculoskeletal disorders. Qual Life Res. 1994;3(1):S85-91. https://doi.org/10.1007/BF00433381

2. Yelin E, Callahan LF, National Arthritis Data Work Group. Special article the economic cost and social and psychological impact of musculoskeletal conditions. Arthritis Rheum. 1995;38(10):1351-62. https://doi.org/10.1002/a rt.1780381002

3. Marx RE. Platelet-rich plasma (PRP): what is PRP and what is not PRP? Implant Dent. 2001;10(4):225-8. https://doi.org/10.1097/00008505-20011 0000-00002.

4. Engebretsen L, Steffen K, Alsousou J, Anitua E, Bachl N, Devilee R, et al. IOC consensus paper on the use of platelet-rich plasma in sports medicine. $\mathrm{Br} \mathrm{J}$ Sports Med. 2010;44(15):1072-81. https://doi.org/10.1136/bjsm.2010.079822.

5. Magra M, Maffulli N. Nonsteroidal antiinflammatory drugs in tendinopathy: friend or foe. Clin J Sport Med. 2006;16(1):1-3. https://doi.org/10.1097/01. jsm.0000194764.27819.5d.

6. Andres BM, Murrell GA. Treatment of tendinopathy: what works, what does not, and what is on the horizon. Clin Orthop Relat Res. 2008;466(7):1539-54. https://doi.org/10.1007/s11999-008-0260-1.

7. Kon E, Filardo G, Di Martino A, Marcacci M. Platelet-rich plasma (PRP) to treat sports injuries: evidence to support its use. Knee Surg Sports Traumatol Arthrosc. 2011;19(4):516-27. https://doi.org/10.1007/s00167-01 0-1306-y.

8. de Jonge S, de Vos RJ, Weir A, van Schie HT, Bierma-Zeinstra SM, Verhaar JA et al. One-year follow-up of platelet-rich plasma treatment in chronic Achilles tendinopathy: a double-blind randomized placebo-controlled trial. Am J Sports Med. 2011;39(8):1623-30. https://doi.org/10.1177/03635465114 04877.

9. Anitua $E$, Sanchez $M$, Nurden AT, Zalduendo $M$, de la Fuente $M$, Orive $\mathrm{G}$, et al. Autologous fibrin matrices: a potential source of biological mediators that modulate tendon cell activities. J Biomed Mater Res A. 2006;77(2):285-93.

10. de Mos M, van der Windt AE, Jahr $H$, van Schie HT, Weinans $H$, Verhaar JA, et al. Can platelet-rich plasma enhance tendon repair? A cell culture study. Am J Sports Med. 2008;36(6):1171-8. https://doi.org/10.1177/036354 6508314430.

11. Grassi A, Napoli F, Romandini I, Samuelsson K, Zaffagnini S, Candrian C, et al. Is platelet-rich plasma (PRP) effective in the treatment of acute muscle injuries? A systematic review and meta-analysis. Sports Med. 2018;48(4):97189. https://doi.org/10.1007/s40279-018-0860-1.

12. Cole BJ, Seroyer ST, Filardo G, Bajaj S, Fortier LA. Platelet-rich plasma: where are we now and where are we going? Sports Health. 2010;2(3):203-10. https://doi.org/10.1177/1941738110366385.

13. Sampson S, Reed M, Silvers $H$, Meng M, Mandelbaum B. Injection of platelet-rich plasma in patients with primary and secondary knee osteoarthritis: a pilot study. Am J Phys Med Rehabil. 2010;89(12):961-9. https://doi.org/10.1097/PHM.0b013e3181fc7edf.

14. Sampson S, Gerhardt M, Mandelbaum B. Platelet rich plasma injection grafts for musculoskeletal injuries: a review. Curr Rev Musculoskelet Med. 2008;1 (34):165-74. https://doi.org/10.1007/s12178-008-9032-5.

15. Hunziker EB, Driesang IM, Morris EA. Chondrogenesis in cartilage repair is induced by members of the transforming growth factor-beta superfamily. Clin Orthop Relat Res. 2001;391:S171-81.
16. Taylor DW, Petrera M, Hendry M, Theodoropoulos JS. A systematic review of the use of platelet-rich plasma in sports medicine as a new treatment for tendon and ligament injuries. Clin J Sport Med. 2011;21(4):344-52. https:// doi.org/10.1097/JSM.0b013e31821d0f65.

17. Pietrzak WS, Eppley BL. Platelet rich plasma: biology and new technology. J Craniofac Surg. 2005;16(6):1043-54

18. Sharma P, Maffulli N. Tendon injury and tendinopathy: healing and repair. J Bone Joint Surg Am. 2005:87(1):187-202. https://doi.org/10.2106/JBJS.D.01850.

19. Woodall J Jr, Tucci M, Mishra A, Asfour A, Benghuzzi H. Cellular effects of platelet rich plasmainterleukin1 release from prp treated macrophages. Biomed Sci Instrum. 2008:44:489-94.

20. Halpern AA, Horowitz BG, Nagel DA. Tendon ruptures associated with corticosteroid therapy. West J Med. 1977:127(5):378-82.

21. Aspenberg P, Virchenko O. Platelet concentrate injection improves Achilles tendon repair in rats. Acta Orthop Scand. 2004;75(1):93-9. https://doi.org/1 0.1080/00016470410001708190

22. Zhou Y, Wang JH. PRP treatment efficacy for tendinopathy: a review of basic science studies. Biomed Res Int. 2016;2016:9103792

23. Aspenberg P. Stimulation of tendon repair: mechanical loading, GDFs and platelets. A mini-review. Int Orthop. 2007;31(6):783-9. https://doi.org/10.1 007/s00264-007-0398-6.

24. Klein MB, Yalamanchi N, Pham H, Longaker MT, Chan J. Flexor tendon healing in vitro: effects of TGF- $\beta$ on tendon cell collagen production. J Hand Surg. 2002;27(4):615-20. https://doi.org/10.1053/jhsu.2002.34004.

25. Molloy T, Wang Y, Murrell GA. The roles of growth factors in tendon and ligament healing. Sports Med. 2003;33(5):381-94. https://doi.org/10.2165/ 00007256-200333050-00004.

26. Auriemma MJ, Tenforde AS, Harris A, Mclnnis KC. Platelet-rich plasma for treatment of chronic proximal hamstring tendinopathy. Regen Med. 2020 15(4):1509-18. https://doi.org/10.2217/rme-2019-0105.

27. Redler A, Proietti L, Mazza D, Koverech G, Vadala A, De Carli A, et al. Rupture of the patellar tendon after platelet-rich plasma treatment: a case report. Clin J Sport Med. 2020;30(1):e20-2. https://doi.org/10.1097/JSM 0000000000000703.

28. Tischer T, Bode G, Buhs M, Marquass B, Nehrer S, Vogt S, et al. Platelet-rich plasma (PRP) as therapy for cartilage, tendon and muscle damage-German working group position statement. J Exp Orthop. 2020;7(1):1-1.

29. Filardo G, Presti ML, Kon E, Marcacci M. Nonoperative biological treatment approach for partial Achilles tendon lesion. Orthopedics. 2010;33(2):120-3.

30. Mishra A Pavelko T. Treatment of chronic elbow tendinosis with buffered platelet-rich plasma. Am J Sports Med. 2006;34(11):1774-8. https://doi.org/1 $0.1177 / 0363546506288850$

31. De Vos RJ, Weir A, van Schie HT, Bierma-Zeinstra SM, Verhaar JA, Weinans H, et al. Platelet-rich plasma injection for chronic Achilles tendinopathy: a randomized controlled trial. JAMA. 2010;303(2):144-9. https://doi.org/10.1 001/jama.2009.1986.

32. Schepull T, Kvist J, Norrman H, Trinks M, Berlin G, Aspenberg P. Autologous platelets have no effect on the healing of human achilles tendon ruptures: a randomized single-blind study. Am J Sports Med. 2011;39(1):38-47. https://doi.org/10.1177/0363546510383515.

33. Kesikburun S, Tan AK, Yılmaz B, Yaşar E, Yazıcıoğlu K. Platelet-rich plasma injections in the treatment of chronic rotator cuff tendinopathy: a randomized controlled trial with 1-year follow-up. Am J Sports Med. 2013 41(11):2609-16. https://doi.org/10.1177/0363546513496542.

34. Scott A, LaPrade RF, Harmon KG, Filardo G, Kon E, Della Villa S, et al. Platelet-rich plasma for patellar tendinopathy: a randomized controlled trial of leukocyte-rich PRP or leukocyte-poor PRP versus saline. Am J Sports Med. 2019;47(7):1654-61. https://doi.org/10.1177/0363546519837954.

35. Perritt S, Roberts M. Flexural-slip structures in the Bushveld complex South Africa? J Struct Geol. 2007;29(9):1422-9. https://doi.org/10.1016/j. jsg.2007.06.008

36. Liu CJ, Yu KL, Bai JB, Tian DH, Liu GL. Platelet-rich plasma injection for the treatment of chronic Achilles tendinopathy: a meta-analysis. Medicine. 2019. 98(16):e15278.

37. Ibrahim DH, El-Gazzar NM, El-Saadany HM, El-Khouly RM. Ultrasound-guided injection of platelet rich plasma versus corticosteroid for treatment of rotator cuff tendinopathy: effect on shoulder pain, disability, range of motion and ultrasonographic findings. Egypt Rheumatol. 2019;41(2):157-61. https://doi.org/10.1016/j.ejr.2018.06.004

38. Chen $X$, Jones IA, Togashi R, Park C, Vangsness $C T$ Jr. Use of platelet-rich plasma for the improvement of pain and function in rotator cuff tears: a 
systematic review and meta-analysis with bias assessment. Am J Sports Med. 2020;48(8):2028-41. https://doi.org/10.1177/0363546519881423.

39. Linnanmäki L, Kanto K, Karjalainen T, Leppänen OV, Lehtinen J. Platelet-rich plasma or autologous blood do not reduce pain or improve function in patients with lateral epicondylitis: a randomized controlled trial. Clin Orthop Relat Res. 2020;478(8):1892-900.

40. Huang K, Giddins G, Wu LD. Platelet-rich plasma versus corticosteroid injections in the management of elbow epicondylitis and plantar fasciitis: an updated systematic review and meta-analysis. Am J Sports Med. 2020; 48(10):2572-85. https://doi.org/10.1177/0363546519888450.

41. Alkhatib N, Salameh M, Ahmed AF, Alkaramany E, Ahmed G, Mekhaimar $\mathrm{MM}$, et al. Platelet-rich plasma versus corticosteroids in the treatment of chronic plantar fasciitis: a systematic review and meta-analysis of prospective comparative studies. J Foot Ankle Surg. 2020;59(3):546-52. https://doi.org/10.1053/j.jfas.2019.10.003.

42. Lin MT, Wei KC, Wu CH. Effectiveness of platelet-rich plasma injection in rotator cuff tendinopathy: a systematic review and meta-analysis of randomized controlled trials. Diagnostics. 2020;10(4):189. https://doi.org/1 0.3390/diagnostics10040189.

43. Glyn-Jones S, Palmer AJ, Agricola R, Price AJ, Vincent TL, Weinans $H$, et al. Osteoarthritis. Lancet. 2015;386(9991):376-87. https://doi.org/10.1016/S01406736(14)60802-3.

44. Rothschild BM, editor. Principles of osteoarthritis: its definition, character, derivation and modality-related recognition: BoD-Books on Demand; 2012

45. Cisternas MG, Murphy L, Sacks JJ, Solomon DH, Pasta DJ, Helmick CG. Alternative methods for defining osteoarthritis and the impact on estimating prevalence in a US population-based survey. Arthritis Care Res. 2016;68(5):574-80. https://doi.org/10.1002/acr.22721.

46. James SL, Abate D, Abate KH, Abay SM, Abbafati C, Abbasi N, et al. Global, regional, and national incidence, prevalence, and years lived with disability for 354 diseases and injuries for 195 countries and territories, 1990-2017: a systematic analysis for the Global Burden of Disease Study 2017. Lancet. 2018;392(10159):1789-858. https://doi.org/10.1016/S0140-6736(18)32279-7.

47. Javaid MK, Kiran A, Guermazi A, Kwoh CK, Zaim S, Carbone L, et al. Individual magnetic resonance imaging and radiographic features of knee osteoarthritis in subjects with unilateral knee pain: the health, aging, and body composition study. Arthritis Rheum. 2012;64(10):3246-55. https://doi. org/10.1002/art.34594.

48. laccarino MA, Borg-Stein J. Platelet-rich plasma in knee osteoarthritis in the athlete. In: Platelet Rich Plasma in Musculoskeletal Practice. London: Springer; 2016. p. 123-46

49. Carr AJ, Robertsson O, Graves S, Price AJ, Arden NK, Judge A, et al. Knee replacement. Lancet. 2012;379(9823):1331-40. https://doi.org/10.1016/S01406736(11)60752-6

50. Pivec R, Johnson AJ, Mears SC, Mont MA. Hip arthroplasty. Lancet. 2012; 380(9855):1768-77. https://doi.org/10.1016/S0140-6736(12)60607-2.

51. Biilsma JW, Berenbaum F, Lafeber FP. Osteoarthritis: an update with relevance for clinical practice. Lancet. 2011;377(9783):2115-26. https://doi. org/10.1016/S0140-6736(11)60243-2.

52. Filardo G, Kon E, Ruiz MT, Vaccaro F, Guitaldi R, Di Martino A, et al. Plateletrich plasma intra-articular injections for cartilage degeneration and osteoarthritis: single-versus double-spinning approach. Knee Surg Sports Traumatol Arthrosc. 2012;20(10):2082-91. https://doi.org/10.1007/s00167011-1837-x.

53. Schwarz UV, Rosier REM, O'Keefe RJ. Articular cartilage biology. J Am Acad Orthop Surg. 2003;11:421.

54. Nguyen RT, Borg-Stein J, Mclnnis K. Applications of platelet-rich plasma in musculoskeletal and sports medicine: an evidence-based approach. PM R. 2011;3(3):226-50. https://doi.org/10.1016/j.pmrj.2010.11.007.

55. Kon E, Buda R, Filardo G, Di Martino A, Timoncini A, Cenacchi A, et al. Platelet-rich plasma: intra-articular knee injections produced favorable results on degenerative cartilage lesions. Knee Surg Sports Traumatol Arthrosc. 2010;18(4):472-9. https://doi.org/10.1007/s00167-009-0940-8.

56. Meheux CJ, McCulloch PC, Lintner DM, Varner KE, Harris JD. Efficacy of intraarticular platelet-rich plasma injections in knee osteoarthritis: a systematic review. Arthroscopy. 2016;32(3):495-505. https://doi.org/10.1016/j.arthro.201 5.08.005.

57. Cook CS, Smith PA. Clinical update: why PRP should be your first choice for injection therapy in treating osteoarthritis of the knee. Curr Rev Musculoskelet Med. 2018;11(4):583-92. https://doi.org/10.1007/s12178-0189524-х.
58. Gobbi A, Karnatzikos G, Mahajan V, Malchira S. Platelet-rich plasma treatment in symptomatic patients with knee osteoarthritis: preliminary results in a group of active patients. Sports Health. 2012;4(2):162-72. https:// doi.org/10.1177/1941738111431801.

59. Patel S, Dhillon MS, Aggarwal S, Marwaha N, Jain A. Treatment with plateletrich plasma is more effective than placebo for knee osteoarthritis: a prospective, double-blind, randomized trial. Am J Sports Med. 2013;41(2): 356-64. https://doi.org/10.1177/0363546512471299.

60. Raeissadat SA, Ghorbani E, Taheri MS, Soleimani R, Rayegani SM, Babaee M, et al. MRI changes after platelet rich plasma injection in knee osteoarthritis (randomized clinical trial). J Pain Res. 2020;13:65-73. https://doi.org/10.2147/ JPR.S204788.

61. Ahmad HS, Farrag SE, Okasha AE, Kadry AO, Ata TB, Monir AA, et al. Clinical outcomes are associated with changes in ultrasonographic structural appearance after platelet-rich plasma treatment for knee osteoarthritis. Int J Rheum Dis. 2018;21(5):960-6. https://doi.org/10.1111/1756-185X.13315.

62. Buendía-López D, Medina-Quirós M, Marín MÁ. Clinical and radiographic comparison of a single LP-PRP injection, a single hyaluronic acid injection and daily NSAID administration with a 52-week follow-up: a randomized controlled trial. J Orthop Traumatol. 2018;19(1):1-9.

63. Samara O, Al-Ajlouni J, Al-Najar M, Saleh M, Al-Ryalat N, Gharaibeh A, et al, Intra-articular autologous platelet lysates produce positive MRI structura changes in early and intermediate knee osteoarthrosis. PJR. 2016;27(1).

64. Kon E, Mandelbaum B, Buda R, Filardo G, Delcogliano M, Timoncini A, et al. Platelet-rich plasma intra-articular injection versus hyaluronic acid viscosupplementation as treatments for cartilage pathology: from early degeneration to osteoarthritis. Arthroscopy. 2011;27(11):1490-501. https:// doi.org/10.1016/j.arthro.2011.05.011.

65. Filardo G, Previtali D, Napoli F, Candrian C, Zaffagnini S, Grassi A. PRP injections for the treatment of knee osteoarthritis: a meta-analysis of randomized controlled trials. Cartilage. 2020:1947603520931170.

66. Migliorini F, Driessen A, Quack V, Sippel N, Cooper B, El Mansy Y, et al. Comparison between intra-articular infiltrations of placebo, steroids, hyaluronic and PRP for knee osteoarthritis: a Bayesian network metaanalysis. Arch Orthop Trauma Surg. 2020:1-8.

67. Zhao J, Huang $H$, Liang G, Zeng LF, Yang W, Liu J. Effects and safety of the combination of platelet-rich plasma (PRP) and hyaluronic acid (HA) in the treatment of knee osteoarthritis: a systematic review and meta-analysis. BMC Musculoskelet Disord. 2020;21:1-2

68. Abdelfattah R, Abdelsabour H, Alzifzaf D, Saad H. Comparison between the effect of platelet rich plasma (PRP) and hyaluronic acid local injection in treatment of thumb carpometacarpal joint osteoarthritis. QJM. 2020; 113(Supplement_1):hcaa064.

69. Kumar A, Kadamb AG, Kadamb KG. Hope, Hype, Hurdles \& Future Perspective for PRP, PRP versus Hyaluronic Acid Injection in Osteoarthritis of Knee: A Review Article. Biol Orthop J. 2020;2(1):e1-2.

70. Gilat R, Haunschild ED, Knapik DM, Evuarherhe A, Parvaresh KC, Cole BJ. Hyaluronic acid and platelet-rich plasma for the management of knee osteoarthritis. Int Orthop. 2020:1-0.

71. Chen Z, Wang C, You D, Zhao S, Zhu Z, Xu M. Platelet-rich plasma versus hyaluronic acid in the treatment of knee osteoarthritis: a metaanalysis. Medicine. 2020;99(11):e19388. https://doi.org/10.1097/MD. 0000000000019388

72. Medina-Porqueres I, Ortega-Castillo M, Muriel-Garcia A. Effectiveness of platelet-rich plasma in the management of hip osteoarthritis: a systematic review and meta-analysis. Clin Rheumatol. 2020:1-2.

73. Hohmann E, Tetsworth K, Glatt V. Is platelet-rich plasma effective for the treatment of knee osteoarthritis? A systematic review and meta-analysis of level 1 and 2 randomized controlled trials. Eur J Orthop Surg Traumatol. 2020;30(6):955-67. https://doi.org/10.1007/s00590-020-02623-4.

74. Dong $Y$, Zhang B, Yang Q, Zhu J, Sun X. The effects of platelet-rich plasma injection in knee and hip osteoarthritis: a meta-analysis of randomized controlled trials. Clin Rheumatol. 2020:1-5.

75. Keene DJ, Alsousou J, Willett K. How effective are platelet rich plasma injections in treating musculoskeletal soft tissue injuries? BMJ. 2016;352:1517.

76. Choi J, Minn KW, Chang H. The efficacy and safety of platelet-rich plasma and adipose-derived stem cells: an update. Arch Plast Surg. 2012;39(6):58592. https://doi.org/10.5999/aps.2012.39.6.585.

77. Pedersen BK, Saltin B. Evidence for prescribing exercise as therapy in chronic disease. Scand J Med Sci Sports. 2006;16(S1):3-63. https://doi.org/1 0.1111/j.1600-0838.2006.00520.x. 
78. Lin I, Wiles L, Waller R, Goucke R, Nagree Y, Gibberd M, et al. What does best practice care for musculoskeletal pain look like? Eleven consistent recommendations from high-quality clinical practice guidelines: systematic review. Br J Sports Med. 2020;54(2):79-86. https://doi.org/10.1136/bjsports-2 018-099878.

79. Shala R. Knee osteoarthritis: through a biopsychosocial lens. Eur J Phys. 2020;21:1.

80. Shala R, Roussel N, Lorimer Moseley G, Osinski T, Puentedura EJ. Can we just talk our patients out of pain? Should pain neuroscience education be our only tool? J Man Manip Ther. 2021;29(1):1-3. https://doi.org/10.1080/1 0669817.2021.1873259.

81. Moraes VY, Lenza M, Tamaoki MJ, Faloppa F, Belloti JC. Platelet-rich therapies for musculoskeletal soft tissue injuries. Cochrane Database Syst Rev. 2014;(4).

\section{Publisher's Note}

Springer Nature remains neutral with regard to jurisdictional claims in published maps and institutional affiliations.

\section{Submit your manuscript to a SpringerOpen ${ }^{\circ}$ journal and benefit from:}

- Convenient online submission

- Rigorous peer review

- Open access: articles freely available online

High visibility within the field

- Retaining the copyright to your article

Submit your next manuscript at $\boldsymbol{\wedge}$ springeropen.com 